Faculdade de Ciências Econômicas UFRGS
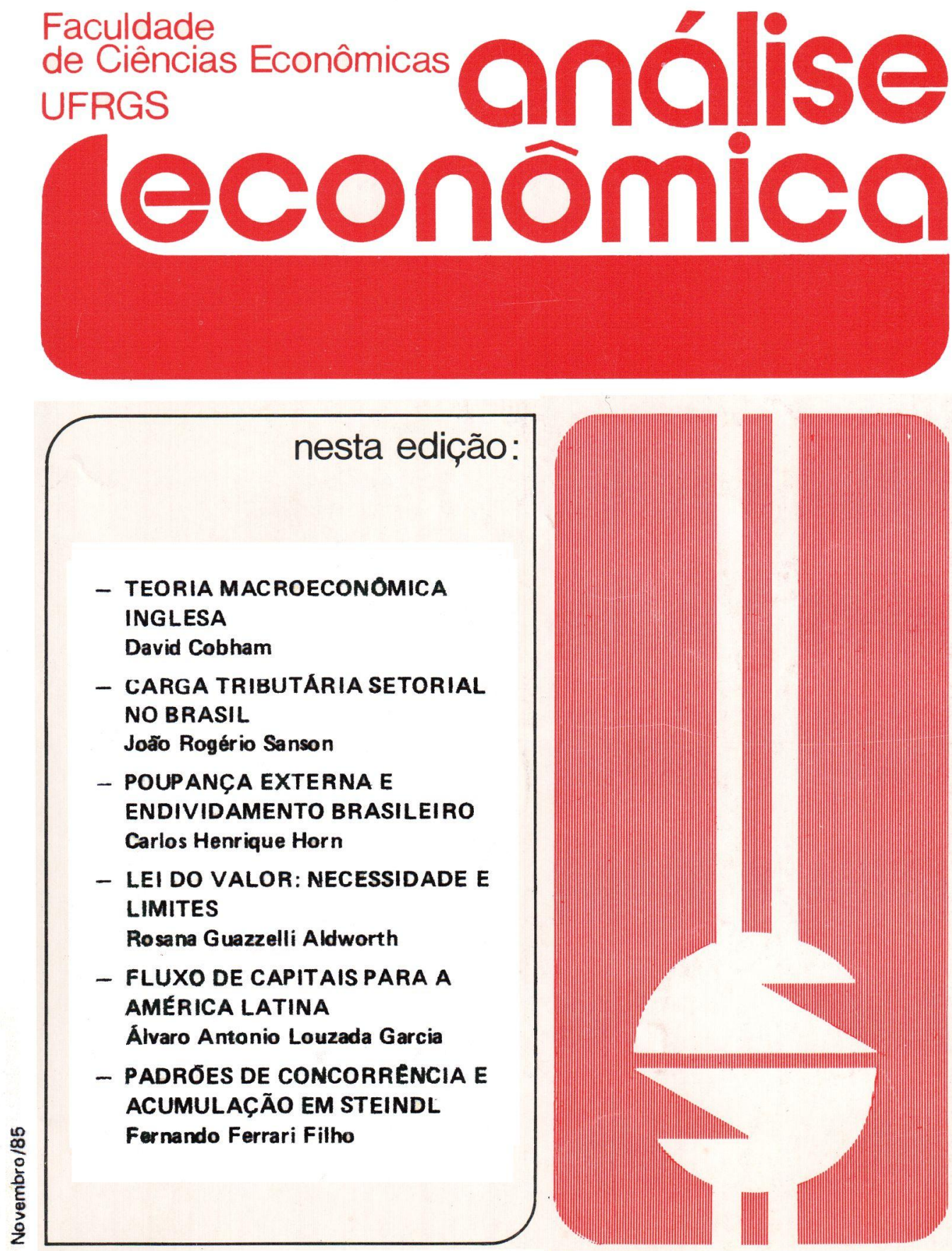

ano 3 
REITOR:Prof. Francisco Ferraz

DIRETOR DA FACULDADE DE CIÊNCIAS ECONÓMICAS:

Prof. Edgar lrio Simm

VICE-DIRETOR: Prof. Walter Meucci Nique

CHEFE DO DEPARTAMENTO DE CIENCIAS ECONOMICAS:

Prof. Renato Batista Masina

CONSELHO EDITORIAL: Prof. Pedro Cezar Dutra Fonsecs (Presidente)

Prof. Achyles Barcelos da Costa

Prof. Carlos Augusto Crusius

Prof. Claudio Francisco Accurso

Prof. Edgar Augusto Lanzer

Prof. Ernani Hickmann

Prof. Juvir Mattuella

Prof. João Rogério Sonson

Profa. Maria Imilda da Costa e Silva

Prof. Nali de Jesus de Souza

Prof. Nuno Renan L. de Figueiredo Pinto

Profa. Otilia Beatriz Kroeff Carrion

Prof. Paulo Alexandre Sphor

Prof. Roberto Camps Moraes

Profa。 Yeda Rorato Crusius

FUNDADOR: Prof. Antonio Carlos Santos Rosa

ANÁLISE ECONÔMICA publica dois números anuais nos meses de março e novembro. O preço da assinatura para 1986 é $\mathrm{Cr} \$ 20,000,00$, a ser pago através de cheque nominal para "Faculdade de Ciências Econômicas - UFRGS". Aceita-se permuta com revistas congêneres. Aceitam-se, também, livros para elaboração de resenhas ou recensões.

Toda a correspondência, material para publicação, assinaturas e permutas devem ser dirigidas a:

Prof. PEDRO CEZAR DUTRA FONSECA

Revista Análise Econômica

Avenida João Pessoa, $52-39$ andar

90.000 - Porto Alegre (RS) - Brasil 


\section{OS PADRÕES DE CONCORRÊNCIA E A ACUMULAÇÃO DE CAPITAL EM STEINDL}

\section{FERNANDO FERRARI FILHO *}

1 - O presente texto, elaborado para Seminário no curso de "Teoria do Valor" do programa de Doutorado em Economia da Universidade de São Paulo durante o primeiro semestre de 1985. procura apresentar umi breve resumo sobre as conexões entre a concorrência e a acumulaçao de capital, contidas no livro de Josef Steindl Maturidade e Estagnação no Capitalismo Americano.

A partir de uma investigação sobre a equação de investimentos do autor, desenvolvida detalhadamente na Parte Segunda de seu livro, o objetivo fundamental constitui-se em demonstrar como uma redução da taxa de acumulação de capital. à medida que o processo de oligopolização se generaliza, característica do capitalismo moderno, tende a conduzir a economia à estagnação.

Neste sentido, passamos a desenvolver as formulações teóricas do autor, apresentadas basicamente nos capítulos $\mathrm{V}, \mathrm{IX}$ e $\mathrm{X}$ de seu livro.

2 - As hipóteses essenciais apresentadas por Steindl sobre os modelos concorrenciais no interior de uma indústria como um todo, sejam modelos competitivos, sejam modelos oligopolistas, são as seguintes: (a) as firmas investem somente na própria indústria; (b) o aumento do capital empresarial da firma é relevante para expandir o nível de investimentos; (c) a taxa de crescimento do mer. cado é dada para a indústria como um todo.

Dadas estas hipóteses genéricas referentes aos modelos concorrenciais, vejamos como Steindl analisa cada padrão de concorrência individualmente.

- Em Doutoramento no Instituto de Pesquisas Econômicas da Universidade de São Paulo.

ANALISE ECONOMICA

\begin{tabular}{l|l|l}
\hline ANO 3 & NO 5 & NOV./85 \\
\hline
\end{tabular}

p. $87-91$ 
No que diz respeito ao modelo de indústria competitiva, Steindl introduz as seguintes hipoteses:

1a - A indústria é composta por firmas progressistas e por firmas marginais, onde as primeiras possuem custos menores em relaçăo às segundas;

2a - a participação no mercado das firmas marginais é significativa;

3a - os preços finais dependem dos custos de produção.

O objetivo de sua análise consiste em explicar como são determinadas as margens de lucro na indústria. Ao tratar este problema, Steindl não está interessado em ajustes de curto prazo, mas na tendência do desenvolvimento, bem como não considera hipóteses limitadas e estáticas, mas, ao contrário, considera os efeitos do progresso técnico como parte essencial do desenvolvimento.

Neste particular, a dinâmica do processo de concorrência se realiza com a adoção do progresso técnico como redutor de custos das firmas, pois a introdução da inovação tecnológica faz com que o excesso de acumulação interna da indústria vis-à-vis ao crescimento do mercado seja resolvido com a eliminação das firmas marginais, na medida em que existe flexibilidade de se reduzir as margens de lucro das firmas progressistas.

Dessa forma, observamos, neste caso, que a redução dos custos das firmas progressistas, proveniente das inovações técnicas, possibilita uma diminuição das margens de lucro para, através da eliminação de algumas firmas existentes, indicar uma tendência à concentração do mercado.

Por outro lado, no que diz respeito ao caso do modelo concorrencial oligopolista a questão é mais complexa.

Trataremos, em primeiro lugar, de adicionar as iıipóteses de Steidl corriidas neste modelo:

1 a - Assim como no caso anterior, a indústria é composta por firmas progressistas e por firmas marginais,onde as primeiras têm menores custos em relação às segundas;

$2^{\mathrm{a}}$ - a participação no mercado das firmas marginais é desprezivel;

$3^{a}$ - a capacidade de resistência à redução de preços por parte das firmas marginais é bastante grande.

Com a introdução da terceira hipótese nos modelos concorrenciais oligopolistas - capacidade de resistência à redução de preços por parte das firmas marginais - observamos que o processo redutor de custos das firmas progressistas, cuja finalidade espe- 


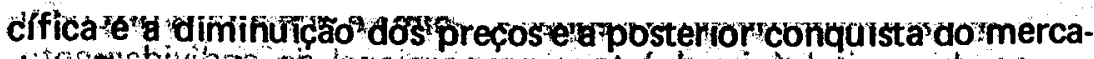

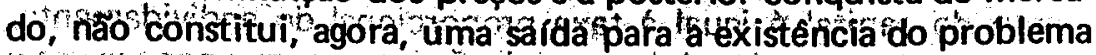
de ocơrrer úm excesso de acúmulaçăo interna da ín dưstria superior ao crescimento do mercado; pois, devido à inflexibilidade à baixa da margem de lucro, a "guerra de preços" se torna ineficiente.

Assim sendo, como as variações na margem de lucro e no preço não constituem mais as características básicas da competição, temos que buscar outras variáveis que possam explicar o processo de ajustamento do sistema.

Neste sentido, segundo Steindl, o grau de utilização e, conseqüentemente, o nível de investimento passam a ser as principais variáveis que explicam este ajustamento.

Porém, Steindl adverte que este ajustamento conduz a economia a um processo de estagnação.

Este processo de ajustamento que conduz a economia à estag. nação, por sua vez, passa a ser nossa preocupação específica conforme veremos a seguir.

3-O processo de estagnação ao qual Steindl se refere passa necessariamente pela construção de um modelo, como descrevemos em seguida.

Consideremos inicialmente a seguinte equação:

$\dot{S}+\dot{K}-\dot{\mathrm{u}}=\dot{\mathrm{g}}+\dot{\mathrm{i}}(1)$, onde $\dot{\mathrm{S}}$ é a taxa de crescimento proporcional das vendas, Ké a taxa de acumulação ćestinada à relação capital/produto, $\dot{u}$ é a taxa de crescimento do grau de utilização do capital, $\dot{\mathrm{g}}$ é a taxa de crescimento do nível de endividamento e $\dot{\mathrm{c}}$ é a taxa de crescimento proporcional do capital próprio.

Como podemos observar, esta é uma equação de crescimento equilibrado, onde o lado esquerdo representa o nivel de investimento - taxa de crescimento do capital - e o lado direito significa o nível de poupança - taxas de acumulação interna e de endividamento.

Antes de procurarmos compreender as implicações da equação (1), consideremos que a formação do potencial da taxa de acumulação interna das firmas seja

$$
\dot{C}=g[f(u, k)-r]+r-a(1-x)^{1}(2) \text {, onde } F(u, k)=e=\text { taxa }
$$
de lucro, tal que $\delta \mathrm{e} / \delta \mathrm{k}>\mathrm{O}$ e $\delta \mathrm{e} / \delta \mathrm{u}<\mathrm{O}$, r é a taxa de juros, $€$ é o consumo básico dos capitalistas como proporção do capital e $(1-x)$ é a propensão marginal a poupar a partir dos lucros que excedem a

Substituindo (2) em (1), temos:

1 - Como nosso objetivo é simplificar a construção do modelo, apresentamos somente o resultado final da equação da taxa de acumulação interna. 


\section{$S+K-U=g+g[F(u, k O-r]+r-a \quad(1-x)(3)$}

Agora, o significado da equação acima é que a taxa de crescimento do capital é igual a taxa proporcional do endividamento, mais a taxa proporcional de acumulação interna, que por sua vez é determinada pelo grau de utilização, pela função lucro e pelos hábitos de poupança dos empresários.

A partir desta equação, o objetivo de Steindl é mostrar que se a taxa de crescimento do capital cair ${ }^{2}$, a forma como se ajusta o lado direito da equação termina por influir negativamente na taxa de crescimento do capital no período seguinte. Isto é, se o nível de investimentos se reduzir ocorre uma queda na poupança mais que proporcional, tal que esta influa depressivamente no nível de investimentos, fazendo com que haja um processo dinâmico estagnacionista.

Suponhamos então que ocorra uma queda na taxa de crescimento do capital. Imediatamente ocorre um ajustamento no lado direito da equaçãó através da redução da taxa de acumulação interna.

Se considerarmos a, $r$ e $\times$ como constante, então a taxa de acumulação interna será influenciada diretamente pela taxa de lucro e pelo grau de utilização. Porém, conforme vimos anteriormente, se numa indústria cuja estrutura seja oligopolizada o ajustamento não se realiza pela redução da margem de luciro - hipóteses de resistência à redução dos preços por parte das firmas marginais logo a variável central do ajustamento é o grau de utilização que, neste caso, decresce para ser compatível com a queda da taxa de acumulação interna.

Neste ponto, surge o argumento básico de Steindl: se o grau de utilização se reduz, então ocorre um aumento da capacidade ociosa; se esta capacidade ociosa inesperada, por sua vez, for maior do que a capacidade ociosa planejada pelos capitalisias, então 0 nível de investimentos cairá ainda mais, tal que haja um crescimento na taxa de desemprego e uma retração na demanda efetiva da economia.

Portanto, se no primeiro momento o nível de pcupança se reduzir mais que proporcionalmente à redução do nível de investimentos, ocorrerá uma queda no segundo momento do nível de investimentos que acentua a continuidade do processo de ajustamento.

2 - Cabe lembrar que Steidl nâo está preocupado com a forma como ocorre a queda na taxa de crescimento do capital (esta pode ser exógena ou estrutural), mas sim com a maneira como ocorre o processo de ajustamento. 
Dessa forma, constatamos que a equação de investimentos de Steindl denota um processo de estagnação e não de movimento cíclico, pois numa economia com estrutura oligopolizada cuja margem de lucro tende a ser inelástica à baixa a redução no grau de utilização conduz à queda do investimento e, conseqüentemente, dinamiza o processo cumulativo que leva o sistema à estagnação.

\section{BIBLIOGRAFIA}

STEINDL, Josef. Maturidade e Estagnaçã̀o no Capitalismo Americano. Abril Cultural, São Paulo, 1983. 